\title{
A study on development of CRM chrysotile in soil
}

\author{
Yun-Ho Choi ${ }^{1, \star}$, Ye-Bin Kwon, Jin-Wook Lee, Nam-Jun Kim, Min-Jong Jeong, \\ Beom-Goo Hwang, Jae-Hyung Lee, Yle-Shik Sun and Bak-Gil Kim \\ Korea Testing \& Research Institute, \\ ${ }^{1}$ Gyeonggi-do Institute of Health \& Environment \\ (Received November 27, 2012; Revised January 16, 2013; Accepted January 16, 2013)
}

\author{
토양 중 백석면 표준물질 개발에 관한 연구 \\ 최윤호 ${ }^{1 \star \star}$ - 권예빈 · 이진욱 · 김남준 · 정민종 - 황범구 · 이재형 · 선일식 · 김박길 \\ 한국화학융합시험연구원, ${ }^{1}$ 경기도보건환경연구원 \\ (2012. 11. 27. 접수, 2013. 1. 16. 수정, 2013. 1. 16. 승인)
}

\begin{abstract}
Interested in NOA (Naturally Occurring Asbestos), Korea as well as the USA has been making geologic maps of asbestos distributed mines and surrounding areas, restoring mines, evaluating hazard, and so on. The result can be used to improve the reliability of analysts and analysis institutions by judging the amount of asbestos and set up PLM (Polarizing Light Microscope) information by analyzing in soil. The certification value of 2 kinds of CRM (Certified Reference Material) was performed by counting total 400 points with EPA 600-R-93-116 method using by PLM. The following is the result of homogeneity and stability of 2 kinds of manufactured CRM analyzed by ANOVA (Analysis of variance) and Regression Analysis. Based on the analyzation, the results are satisfied with homogeneity and long-term stability. The analyzed certification value of CRM includes the range of minimum and maximum value of point counting result for chrysotile; low concentration-1\% (range, 0.25 3.00), high concentration-4\% (range, 2.25 5.50).

요 약: 세계적으로 석면에 관한 다양한 연구사례가 발표되고 있는 가운데, 최근 미국을 비롯해 국내 또 한 NOA (Naturally Occurring Asbestos)에 대한 관심으로 석면분포 광산 및 주변지역의 지질도 작성, 광 산복원, 유해성 평가 등을 실시하고 있다. 본 연구에서는 토양 중 백석면을 분석하는 과정에서 정성, 정 량 평가용 표준물질을 개발함으로써 분석결과에 대한 분석기관 및 분석자의 신뢰성 향상과 더불어 광학 현미경의 기초자료를 확보고자 한다. 석면분석은 정성분석과 정량분석으로 구분하였으며, 석면정량을 위 한 방법은 EPA 600-R-93-116의 점계수법(point counting)으로 총 400지점을 계수하는 방법으로 실시하였 다. 제작된 2종에 해당하는 인증표준물질(CRM, Certified Reference Material)을 분산분석과 회귀분석을 이용하여 각각 균질성과 장기 안정성을 확인한 결과 이상이 없음을 확인하였다. 인증표준물질의 인증값 은 점계수 결과의 최소값에서 최대값에 이르는 결과를 포함하며 저농도, $1 \%$ (범위, 0.25 3.00), 고농도, $4 \%$ (범위, 2.25 5.50)로 산출되었다.
\end{abstract}

Key words: chrysotile, soil, CRM, NOA

Corresponding author

Phone : +82-(0)31-250-2628 Fax : +82-(0)31-250-2629

E-mail : yunho238@gg.go.kr 


\section{1. 서 론}

석면은 인체에 노출시 석면폐증(석면에 의한 폐의 섬유화), 폐암, 악성중피종(흉막이나 복막에 생기는 암) 을 유발할 수 있는 물질로, 국제암센터(IARC)에서는 Group 1, 미국 $\mathrm{EPA}$ 의 통합 유해성 정보시스템(IRIS) 에서는 Group A등급의 인체발암물질로 분류하고 있 다. 석면의 흡입량에 따라 다르지만 잠복기간을 석면 폐증은 25 40년, 폐암이나 중피종은 15 30년으로 두 고 있어 석면으로 인한 피해증상이 단시간에 나타나 지 않는다. ${ }^{1-2}$

석면의 종류별 인체 유해성 정도는 청석면>갈석 면>백석면 순이고, 청석면과 갈석면은 백석면보다 날 카롭고 폐에 들어가도 백석면은 어느 정도 용해된다 고 알려져 있으나 청석면은 폐에서 용해되는데 100년 이상 소요된다. ${ }^{3}$

국내에서는 '97년 갈석면, 청석면에 이어 '03년부터 석면 3종(트레몰라이트 석면, 악티놀라이트 석면, 안 소필라이트 석면)의 제조 - 수입 · 양도 - 제공 - 사용이 금지되었으나, 백석면은 노동부 장관의 허가를 받아 수입 - 사용 등이 가능하여 '05년에는 6,477톤을 수입 하였다. ${ }^{4}$

세계적으로 석면에 관한 다양한 연구사례가 발표되 고 있는 가운데, 최근 미국을 비롯한 선진국 등에서 $\mathrm{NOA}$ (Naturally Occurring Asbestos)에 대한 관심이 대 두되고 있다. 우리나라도 2009년을 시작으로 NOA에 대한 관심으로 석면분포 광산 및 주변지역의 지질도 작성, 광산복원, 유해성 평가 등의 영향조사를 실시하 고 있다. ${ }^{5}$ 특히 석면이 함유된 토양을 분석하는데 있 어 석면과 유사한 광물질의 혼재로 인하여 석면 평가 의 오류가 발생할 수 있는 경우가 종종 있는 것으로 알려져 있다. 따라서 본 연구는 토양 중 백석면을 분 석하는 과정에서 표준물질을 개발함으로써 분석결과 에 대한 분석기관 및 분석자의 신뢰성 향상을 목적으 로 한다.

\section{2. 연구방법}

\section{1. 후보물질 제조}

후보물질 제조에 사용되는 백석면은 (주)경안인더스 트리에서 제공받은 원료를 사용하였으며, 제조를 위해 사용된 백석면에 대하여는 광학적 성질과, 모양, 성분 등을 확인하기 위하여 편광현미경(LV $100 \mathrm{POL}$, NIKON)과 주사전자현미경(Nova Nano SEM 400, FEI)

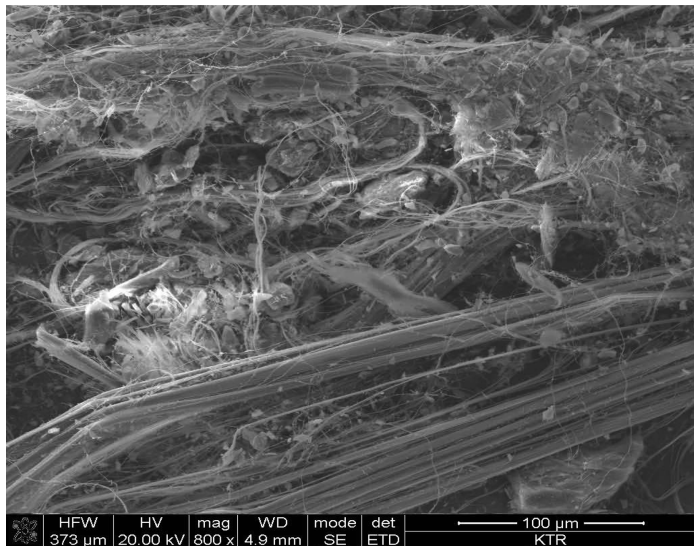

Fig. 1. Chrysotile image by SEM.

Table 1. Optical properties of chrysotile

\begin{tabular}{cc}
\hline \hline Character of chrysotile & Description \\
\hline Morphology & Wavy, Silky, Curly Fibers \\
Aspect ratio & $>10: 1$, Mean $>20: 1$ \\
Color & Colorless, White \\
Pleochroism & None \\
Extinction type & Parallel \\
Refractive index & $1.54 \sim 1.55$ \\
Birefringence & Law $(0.007)$ \\
Sign of eongation & + \\
RI Liquid, Color & $1.550^{\mathrm{HD}}$, Blue - Magenta \\
$\%$ Asbestos & $>95 \%$ \\
\hline
\end{tabular}

을 사용하여 원료물질을 Fig. 1, Table 1에 의해 평가 하였다. 표준물질 제조는 일반적인 자연발생 석면지역 의 토양재질과 유사한 석면프리 토양과 백석면 표준 물질을 균질하게 혼합하여 제작하였다. 혼합하기 전에 백석면의 원료는 석면섬유의 뭉침 현상을 제거하기 위하여 습식침강 방법을 이용하여 입도크기를 106 $\mu \mathrm{m}$ (No.140) $45 \mu \mathrm{m}$ (No.325) 조절 후 건조하여 혼합 하였다. 또한, 매트리스 시료로 사용된 석면프리 토양 의 경우에는 토양고유의 미세분말로 인한 뭉침 현상 을 최소화 하기위하여 $25 \mu \mathrm{m}$ (No.500)의 습식 체가름 을 실시하여 체불통과분의 원료를 이용하였다. 건조된 백석면 원료와 석면프리 토양원료를 일정 비율로 혼 합하여 핸드 밀(A11B, IKA) 또는 자동 체가름기 (Analysette3, FRITSCH)를 이용하여 균질하게 혼합이 되도록 수차례 작업을 반복하였다. 전체적인 제조방법 은 Fig. 2와 같다.

블렌딩과 분쇄가 끝나고, 입도조절까지 끝난 시료는 $30 \mathrm{~mL}$ 부피의 유리제 용기에 넣고 별도의 플라스틱 


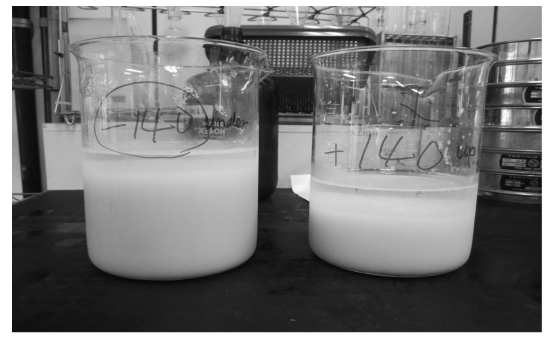

(a) Raw-material stirring and wet sedimentation

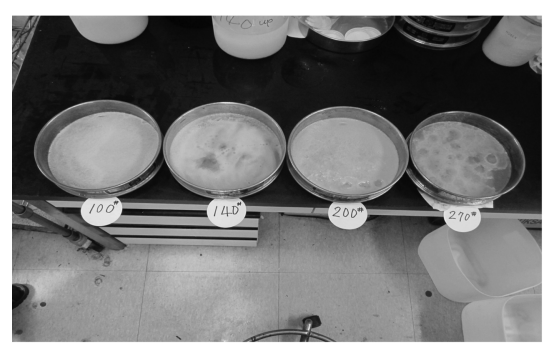

(c) Particle size separation and drying

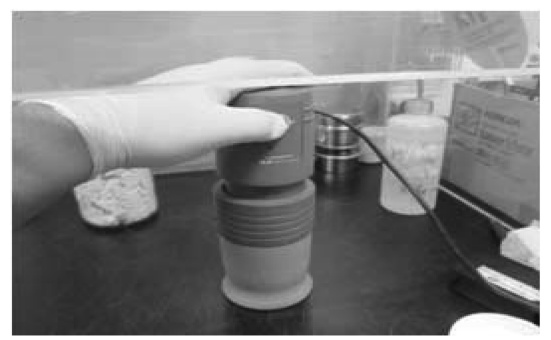

(e) Mixtures using a hand mill

Fig. 2. Manufacture process of CRM preliminary material.

포장용기에 넣어 보관한다.

\section{2. 후보물질 소급성 확보}

본 연구의 소급성을 확립하기 위해 사용된 표준물 질은 미국 NIST(National Institute of Standards and Technology)에서 제작 및 판매된 석면표준물질 SRM $1866 \mathrm{~b}$ 의 백석면을 사용하였다. 후보물질 소급성 확보 를 위해 사용된 편광현미경(PLM)은 파장을 변화시키 는 보정판, 시료를 회전하며 관찰할 수 있는 재물대, 편광기능을 위한 편광판이 갖추어진 장치로써 대물렌 즈와 접안렌즈의 조합으로 400 배의 배율을 가진 광학 적으로 색을 나타나게 하는 분산염색 대물렌즈로 구 성된 편광현미경을 사용하였다. ${ }^{6}$ 소급성 확보를 위한 확인은 EPA-600/R-93-116(Method for the Determination Vol. 26, No. 1, 2013

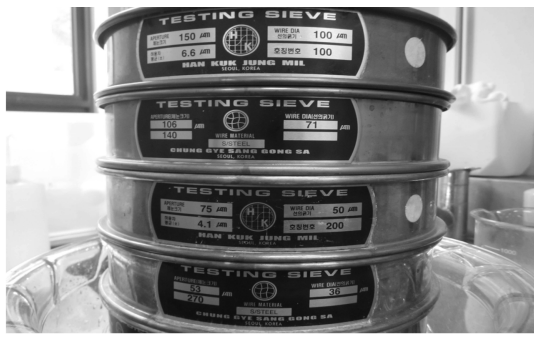

(b) Separating the particle size of the chrysotile

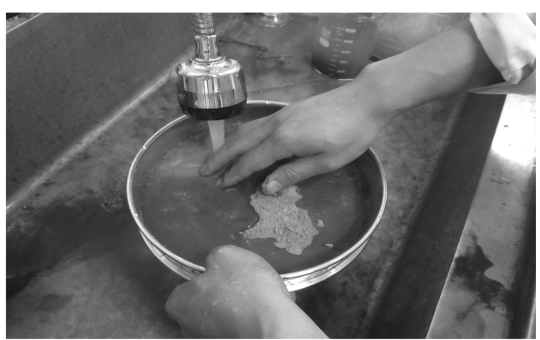

(d) The wet sieve of asbestos-free soil

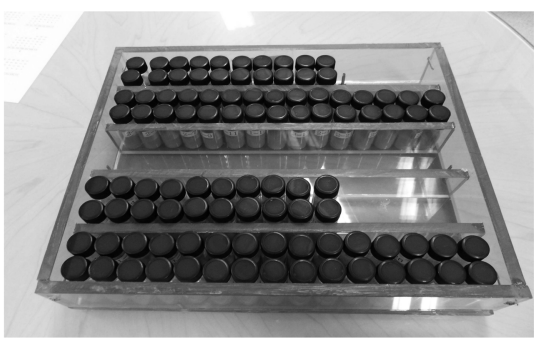

(f) Bottling storage

of Asbestos in Bulk Building Materials)에 규정된 편 광현미경을 이용하여 석면의 굴절률을 평가하여 토양 중 백석면에 대한 정성분석 그리고 저농도, 고농도에 대한 정량값의 범위를 제시하였다. ${ }^{7}$

\subsection{1. 후보물질 소급성 확보 절차}

Refractive index liquids(DS method)를 이용하여 실 험실 온도를 측정하고 석면을 분석하기 위한 해당 굴 절액을 선택하여 각 파장에 따른 굴절률을 확인한다. 소급성 절차는 다음과 같다. ${ }^{8}$

(1) 실험실의 온도를 기록한다. 오차는 $\pm 2{ }^{\circ} \mathrm{C}$ 를 기 준으로 한다.

(2) 적당한 굴절액을 선택하여 석면섬유의 슬라이드 를 제작한다. 


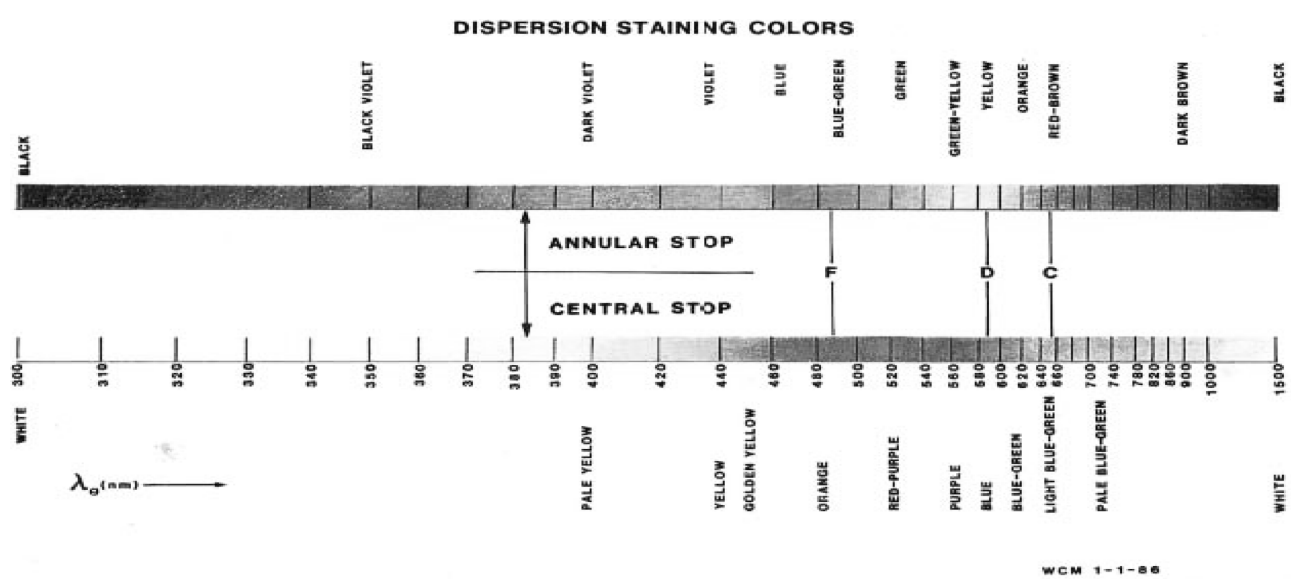

Fig. 3. Chart of dispersion staining colors (McCrone, 1987).

Table 2. Converting dispersion staining colors to matching wavelengths (McCrone, 1987).

\begin{tabular}{|c|c|c|c|c|}
\hline \multirow{2}{*}{$\begin{array}{c}\text { Matching wavelength, } \mathrm{nm} \\
\text { Annular stop }\end{array}$} & \multicolumn{2}{|c|}{ Particle edge colors 1} & \multirow{2}{*}{\multicolumn{2}{|c|}{$\begin{array}{c}\text { Becke line colors2 } \\
\text { Liquid }\end{array}$}} \\
\hline & Central Stop & Particle & & \\
\hline$<340$ & Black violet & White & White & $\mathrm{X}$ \\
\hline 400 & Dark violet & Pale yellow & Pale yellow & $\mathrm{X}$ \\
\hline 430 & Violet & Yellow & Pale yellow & $\mathrm{X}$ \\
\hline 455 & Blue & Golden yellow & Yellow & Violet \\
\hline 485 & Blue-green & Orange & Orange & Violet \\
\hline 520 & Green & Red purple & Orange-red & Violet-blue \\
\hline 560 & Yellow-green & Purple & Red-orange & Blue-violet \\
\hline 595 & Yellow & Deep blue & Red & Blue \\
\hline 625 & Orange & Blue-green & Faint red & Blue \\
\hline 660 & Red-brown & Light blue-green & X & Blue-green \\
\hline 700 & Dark red-brown & Pale blue-green & $\mathrm{X}$ & Pale blue-green \\
\hline 1500 & Black-brown & Very pale blue-green & $\mathrm{X}$ & Very pale blue-green \\
\hline
\end{tabular}

Table 3. Conversion table for calibrating RI liquid 1.550 (Series E). using cargille calibrated refractive index solid

\begin{tabular}{|c|c|c|c|c|c|c|}
\hline$\lambda \mathrm{o},(\mathrm{nm})$ & $20^{\circ} \mathrm{C}$ & $22{ }^{\circ} \mathrm{C}$ & $24{ }^{\circ} \mathrm{C}$ & $26^{\circ} \mathrm{C}$ & $28^{\circ} \mathrm{C}$ & $30{ }^{\circ} \mathrm{C}$ \\
\hline 520 & 1.542 & 1.543 & 1.544 & 1.545 & 1.546 & 1.547 \\
\hline 540 & 1.544 & 1.545 & 1.546 & 1.547 & 1.548 & 1.549 \\
\hline 560 & 1.546 & 1.547 & 1.548 & 1.549 & 1.550 & 1.551 \\
\hline 580 & 1.548 & 1.549 & 1.550 & 1.551 & 1.551 & 1.552 \\
\hline 600 & 1.549 & 1.550 & 1.551 & 1.552 & 1.553 & 1.554 \\
\hline 620 & 1.551 & 1.552 & 1.553 & 1.554 & 1.554 & 1.555 \\
\hline 640 & 1.552 & 1.553 & 1.554 & 1.555 & 1.556 & 1.557 \\
\hline 660 & 1.553 & 1.554 & 1.555 & 1.556 & 1.557 & 1.558 \\
\hline 680 & 1.554 & 1.555 & 1.556 & 1.557 & 1.558 & 1.559 \\
\hline 700 & 1.555 & 1.556 & 1.557 & 1.558 & 1.559 & 1.560 \\
\hline
\end{tabular}

Reference: Shu-Chun Su, refractive index liquid calibration using calibrated refractive index solids, 2002.

예) 백석면 : $1.550^{\mathrm{HD}}$

(3) 섬유를 수평방향으로 조정하고 Fig. 3 또는 Table 2로부터 CSDS (Central Stop Dispersion Staining)
색상을 확인한다.

(4) 온도에 따른 굴절률을 Table 3에서 선택하여 백 석면의 특성값을 확인한다. ${ }^{9}$ 
Table 4. Chrysotile wavelength at temperature $24{ }^{\circ} \mathrm{C}$

\begin{tabular}{cccccccccccc}
\hline \hline$\lambda \mathrm{o},(\mathrm{nm})$ & 520 & 540 & 560 & 580 & 600 & 620 & 640 & 660 & 680 & 700 \\
\hline $24{ }^{\circ} \mathrm{C}$ & 1.544 & 1.546 & 1.548 & 1.550 & 1.551 & 1.553 & 1.554 & 1.555 & 1.556 & 1.557 \\
\hline
\end{tabular}

\subsection{2. 후보물질 소급성 확보 결과}

(주)경안인더스트리에서 공급받은 석면을 실험실 온도조건 $24{ }^{\circ} \mathrm{C}$ 에서, 백석면 표준굴절액 $1.550^{\mathrm{HD}}$ (Cargille Refractive Index Liquid)를 사용하여, 표준 굴절액(DS method)을 사용하여 CSDS 색상을 확인 한 결과 백석면의 광학적 특징을 확인하였으며 결과 는 Table 4와 같다.

\section{3. 석면분석 방법}

석면 분석방법은 크게 정성평가와 정량평가로 구분 될 수 있는데, 본 연구에서는 시험물질의 형태(morphology), 굴절률(refractive index), 다색성(pleochroism), 색 깔(color), 복굴절(birefringence), 소광특성(extinction), 신장율 부호(sign of elongation), 분산염색의 특성 (interference color) 등 EPA-600/R-93-116에 규정된 편 광현미경을 이용한 섬유나 광물의 광학적 특성분석을 통하여 정성분석과 점계수법(point counting method)에 의해 정량평가를 수행하였다. ${ }^{10-11}$

편광현미경을 이용한 점계수법 농도의 산출식은 다 음과 같다.

$$
\mathrm{C}=\frac{\mathrm{A} \times 100}{\mathrm{D}}
$$

여기서,

$\mathrm{C}$ : 분석대상 후보물질의 농도(\%)

$\mathrm{A}$ : 계수된 석면섬유의 개수

$\mathrm{D}$ : 계수된 비어있지 않은 지점의 수(400 points)

\section{4. 후보물질 특성값 부여 방법}

\subsection{1. 균질도 연구방법}

제조한 후보물질의 균질도를 확인하기 위해 50 개의 병입된 시료 중 병입 순서에 따라 일정한 간격으로 9 개의 시료를 선정하여 각 시료마다 3회 반복 측정하 여 평가하였다. 측정방법은 편광현미경을 통한 점계수 법을 이용하였으며, 균질도에 대한 평가는 일원분산분 석의 $\mathrm{F}$ 기각치와 $\mathrm{F}$ 비를 비교한 결과값에 대하여 $\mathrm{F}$ 비가 $\mathrm{F}$ 기각치보다 작으며, $\mathrm{P}$ 값으로부터 $95 \%$ 신뢰 수준에서 9 개 후보물질의 반복측정값에 대한 통계값 으로 평가하였다. ${ }^{12-13}$

\subsection{2. 안정도 연구방법}

제조한 후보물질의 안정성은 운송과정에서 예상될 수 있는 온도, 습도변화에 따른 안정성을 현장실험실 에서 조건을 변화시키면서 조절할 수 있다. 일반적으 로 Bulk 상태의 물질인 석면은 장기간 매우 안정한 것으로 알려져 있지만 보관시에는 자동 습도조절이 가능한 데시케이터에 보관한다.

후보물질의 안정도 평가를 위한 방법은 일정한 간 격으로 5 개의 시료를 선정하여 시료마다 5 회 반복 측 정한 평균값을 6 개월 간격으로 최초 1 차 정량 후 6 개 월, 12 개월간의 장기 안정도를 평가하였다. 측정값의 평가는 회귀분석을 통하여 P-값> $0.05,95 \%$ 신뢰수준 에서 평가하였다. ${ }^{12-13}$

\subsection{3. 인증값 연구방법}

각 후보물질의 인증값은 50 개의 병입된 시료 중 병입 순서에 따라 일정한 간격으로 10 개의 시료를 선정하여 각 시료마다 2회 반복 측정하여 평가하였 다. 분석은 편광현미경을 이용하여 석면정량을 위한 점계수법으로 총 400지점을 계수하는 방법으로 실 시하였으며, 하나의 시료에 대해 최소 8 개의 슬라이 드를 만들어 분석하였다. 정량평가는 1 개의 슬라이 드당 50 개 지점을 계수하여 십자선에 겹치는 물질 이 있을 때 1 개의 지점으로 계수하며, 전체 400 지점 중 계수 된 석면섬유의 수로 나누어 계산한다. 이와 같은 방법으로 400 지점을 계수하여 석면섬유의 평 균값은 각각 10 개의 후보물질에 대하여 400 지점에 서 얻어진 결과의 평균값이다. 인증값의 범위(range) 는 석면정량을 위해 분석한 개별적인 점계수 결과의 최소값에서 최대값에 이르는 결과를 포함하여 나타 내었다. ${ }^{12-13}$

\section{3. 결과 및 고찰}

\section{1. 균질도 평가 결과}

저농도, 고농도 후보물질의 균질도를 평가하기 위해 일원분산분석의 $\mathrm{F}$ 기각치와 $\mathrm{F}$ 비를 비교하여, $\mathrm{P}$ 값으 로부터 $95 \%$ 신뢰수준에서 균질도를 통계값으로 평가 
Table 5. Analysis results of homogeneity

Unit: $\%$

\begin{tabular}{cccc}
\hline \hline Sample ID & \multicolumn{2}{c}{ Times of measurement } \\
\cline { 2 - 4 } (Low concentration) & 1 & 2 & 3 \\
\hline CH-SOIL-01-05 & 0.25 & 1.25 & 0.75 \\
CH-SOIL-01-10 & 2.00 & 0.50 & 1.75 \\
CH-SOIL-01-15 & 0.50 & 1.25 & 2.00 \\
CH-SOIL-01-20 & 0.75 & 0.75 & 1.50 \\
CH-SOIL-01-25 & 1.75 & 2.00 & 0.50 \\
CH-SOIL-01-30 & 0.50 & 1.00 & 0.50 \\
CH-SOIL-01-35 & 0.50 & 1.50 & 1.75 \\
CH-SOIL-01-40 & 0.50 & 1.00 & 2.00 \\
CH-SOIL-01-45 & 0.75 & 1.25 & 0.50 \\
Ave & 0.83 & 1.17 & 1.25 \\
Stdev & 0.61 & 0.43 & 0.67 \\
\hline Sample ID & Times & of measurement \\
\cline { 2 - 4 } (High concentration) & 1 & 2 & 3 \\
\hline CH-SOIL-02-05 & 2.75 & 3.25 & 3.00 \\
CH-SOIL-02-10 & 5.00 & 4.25 & 3.75 \\
CH-SOIL-02-15 & 5.25 & 5.00 & 4.75 \\
CH-SOIL-02-20 & 3.75 & 3.00 & 2.75 \\
CH-SOIL-02-25 & 3.00 & 3.25 & 5.00 \\
CH-SOIL-02-30 & 5.00 & 5.00 & 3.00 \\
CH-SOIL-02-35 & 3.00 & 3.25 & 5.25 \\
CH-SOIL-02-40 & 4.25 & 4.50 & 3.75 \\
CH-SOIL-02-45 & 4.00 & 3.75 & 3.25 \\
Ave & 4.00 & 3.92 & 3.83 \\
Stdev & 0.95 & 0.79 & 0.94 \\
\hline & & &
\end{tabular}

하였으며, 그 분석값은 Table 5에 요약하였다. 일원분 산분석법의 통계적 원리를 이용한 토양 중 백석면의 균질도 평가 결과 저농도의 경우 $\mathrm{F}$ 비 $=0.609<\mathrm{F}$ 기각 치 $=2.510$ 이므로 $95 \%$ 신뢰수준에서 균질함을 Table 6 에서 확인할 수 있다. 고농도 또한 $\mathrm{F}$ 비< $<\mathrm{F}$ 기각치 이므로 제조된 후보물질은 모두 균질함을 Table 6에서 확인하였다. ${ }^{14-15}$

\section{2. 안정도 평가 결과}

저농도, 고농도 후보물질 안정도 평가를 위해 회귀 분석의 P-값>0.05, $95 \%$ 신뢰수준에서 안정도를 통계 적으로 평가하였으며, 그 분석값은 Table 7에 요약하 였다. 회귀분석 통계적 원리를 이용한 토양 중 백석면 의 안정도 평가결과 저농도인 경우 P-값 $=0.272$ 이므 로, $95 \%$ 신뢰수준에서 장기안정성을 Table 8와 Fig. 4 에서 확인할 수 있다. 고농도 또한 $\mathrm{P}$-값>0.05 이므로 제조된 후보물질은 모두 장기안정성을 Table 8와 Fig. 5 에서 확인하였다. ${ }^{14-15}$

\section{3. 인증값 평가 결과}

후보물질의 인증값은 석면의 정량분석을 위한 점계 수 결과의 최소값에서 최대값에 이르는 결과를 포함

Table 6. Evaluation results of homogeneity

\begin{tabular}{|c|c|c|c|c|c|c|}
\hline Low concentration & & & & & & \\
\hline Source of variation & SS & $\mathrm{df}$ & MS & $F$ & P-value & F crit \\
\hline Between groups & 1.917 & 8 & 0.240 & 0.609 & 0.759 & 2.510 \\
\hline Within groups & 7.083 & 18 & 0.394 & & & \\
\hline Total & 9.000 & 26 & & & & \\
\hline \multicolumn{7}{|l|}{ High concentration } \\
\hline Source of variation & SS & $\mathrm{df}$ & MS & $\mathrm{F}$ & P-value & F crit \\
\hline Between groups & 9.250 & 8 & 1.156 & 2.031 & 0.101 & 2.510 \\
\hline Within groups & 10.250 & 18 & 0.569 & & & \\
\hline Total & 19.500 & 26 & & & & \\
\hline
\end{tabular}

Table 7. Analysis results of stability

\begin{tabular}{|c|c|c|c|c|c|c|}
\hline Sample (Low concentration) & CH-S-01-05 & CH-S-01-15 & CH-S-01-25 & CH-S-01-35 & CH-S-01-45 & Mean \\
\hline \multicolumn{7}{|l|}{ Term(month) } \\
\hline 0 & 1.00 & 0.90 & 1.30 & 1.05 & 1.05 & 1.06 \\
\hline 6 & 1.05 & 1.05 & 1.15 & 1.25 & 1.65 & 1.23 \\
\hline 12 & 0.90 & 1.10 & 1.35 & 1.15 & 1.75 & 1.25 \\
\hline Sample (High concentration) & \multirow{2}{*}{ CH-S-02-05 } & \multirow{2}{*}{ CH-S-02-15 } & \multirow{2}{*}{ CH-S-02-25 } & \multirow{2}{*}{ CH-S-02-35 } & \multirow{2}{*}{ CH-S-02-45 } & \multirow{2}{*}{ Mean } \\
\hline Term(month) & & & & & & \\
\hline 0 & 3.80 & 3.70 & 3.90 & 3.95 & 3.85 & 3.84 \\
\hline 6 & 3.80 & 3.65 & 3.80 & 3.75 & 4.35 & 3.87 \\
\hline 12 & 3.90 & 4.05 & 3.95 & 3.85 & 4.35 & 4.02 \\
\hline
\end{tabular}


Table 8. Evaluation results of stability

Low concentration

\begin{tabular}{|c|c|c|c|c|c|c|}
\hline & $\overline{\mathrm{df}}$ & SS & MS & $\bar{F}$ & Significance $\mathrm{F}$ & \\
\hline Regression & 1 & 0.018 & 0.018 & 4.813 & 0.272 & \\
\hline Residual & 1 & 0.004 & 0.004 & & & \\
\hline \multirow[t]{2}{*}{ Total } & 2 & 0.022 & & & & \\
\hline & Coefficients & Standard error & t Stat & P-value & Lower 95\% & Upper $95 \%$ \\
\hline Intercept & 1.085 & 0.056 & 19.409 & 0.033 & 0.375 & 1.795 \\
\hline $\mathrm{X}$ Variable 1 & 0.016 & 0.007 & 2.194 & 0.272 & -0.076 & 0.108 \\
\hline \multicolumn{7}{|l|}{ High concentration } \\
\hline & df & SS & MS & $\mathrm{F}$ & Significance F & \\
\hline Regression & 1 & 0.016 & 0.016 & 6.750 & 0.234 & \\
\hline Residual & 1 & 0.002 & 0.002 & & & \\
\hline \multirow[t]{2}{*}{ Total } & 2 & 0.019 & & & & \\
\hline & Coefficients & Standard error & t Stat & P-value & Lower 95\% & Upper 95\% \\
\hline Intercept & 3.820 & 0.045 & 85.418 & 0.007 & 3.252 & 4.388 \\
\hline $\mathrm{X}$ Variable 1 & 0.015 & 0.006 & 2.598 & 0.234 & -0.058 & 0.088 \\
\hline
\end{tabular}

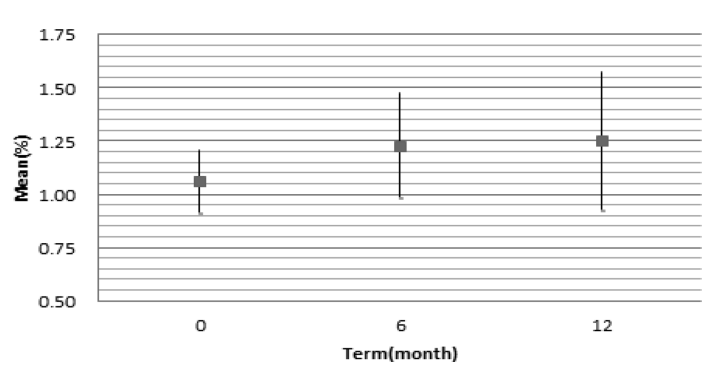

Fig. 4. Graphical illustration of stability for low concentration.

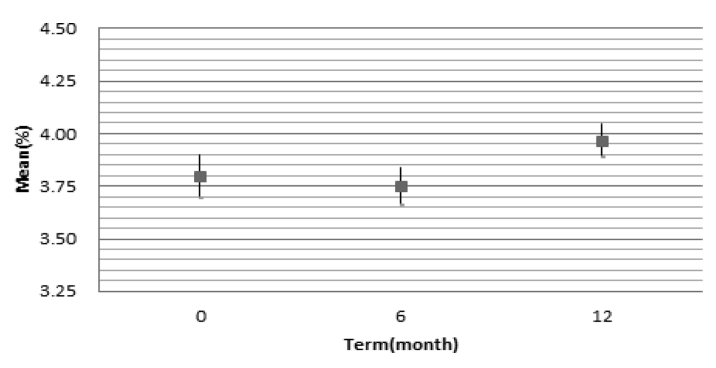

Fig. 5. Graphical illustration of stability for high concentration.

하며, 토양 중 백석면의 인증값 결과는 Table 9과 같 다. 개발된 표준물질의 인증값 활용을 통해 분석자는 분석하고자 하는 시료와의 비교 평가를 바탕으로 정 확한 정량값을 평가하였는지 그 결과에 대한 교정 및 방법의 적절성을 확인할 수 있으며, 또한 분석자 및 분석기관의 결과값에 대한 신뢰성이 향상되어 질 것 으로 기대된다.
Table 9. The results of certification

\begin{tabular}{cccc}
\hline \hline Sample ID & Mean(\%) & $\begin{array}{c}\text { Range(\%), 95\% } \\
\text { Confidence interval }\end{array}$ \\
\hline CH-SOIL-Low concentration & 1 & $0.25 \sim 3.00$ \\
CH-SOIL-High concentration & 4 & $2.25 \sim 5.50$ \\
\hline Table 10. Acceptable error for PLM analysis \\
\hline \hline \% Area & Acceptable & $\%$ Area & Acceptable \\
asbestos & mean result & asbestos & mean result \\
\hline 1 & $>0 \sim 3 \%$ & 50 & $40 \sim 60 \%$ \\
5 & $>1 \sim 9 \%$ & 60 & $50 \sim 70 \%$ \\
10 & $5 \sim 15 \%$ & 70 & $60 \sim 80 \%$ \\
20 & $10 \sim 30 \%$ & 80 & $70 \sim 90 \%$ \\
30 & $20 \sim 40 \%$ & 90 & $80 \sim 100 \%$ \\
40 & $30 \sim 50 \%$ & 100 & $90 \sim 100 \%$ \\
\hline
\end{tabular}

\section{4. 개발된 인증표준물질과 EPA기준 비교}

미국의 대표적인 석면관리 기관인 $\mathrm{EPA}$ (Environmental Protection Agency)에서는 분석자의 정확한 석 면평가를 위해서 Table 10 과 같이 편광현미경을 이용 한 일반적인 정량분석 허용오차를 권고하고 있다. ${ }^{16}$

$\mathrm{EPA}$ 에서 제시한 허용오차를 바탕으로 개발된 인증 표준물질을 비교한 결과 연구의 목적인 분석기관으로 부터의 결과값에 대한 허용오차 범위와 석면분석의 한 특징으로 논의되고 있는 석면정량분석의 범위에 만족하는 결과를 얻었다. 즉 토양 중 백석면 저농도의 경우 개발된 인증표준물질의 범위 $0.25 \sim 3.00 \%$ 가 EPA 
Table 11. The results of certification and EPA error

\begin{tabular}{cccccc}
\hline \hline Types of asbestos & Concentration & Mean(\%) & Range(\%) & EPA error range & Note \\
\hline \multirow{2}{*}{ Chrysotile in soil } & Low concentration & 1 & $0.25 \sim 3.00$ & $>0 \sim 3 \%$ & Satisfied \\
& High concentration & 4 & $2.25 \sim 5.50$ & $>1 \sim 9 \%$ & Satisfied \\
\hline
\end{tabular}

의 오차범위 $>0 \sim 3 \%$ 에 포함됨을 확인할 수 있다. 같은 방법으로 개발된 고농도의 석면에 대하여 $\mathrm{EPA}$ 오차 범위와 개발된 인증표준물질의 범위를 비교한 결과 만족하는 수준을 나타내었다. 이것은 개발된 인증표준 물질이 정량분석 허용오차를 만족하므로 본 연구의 목적이었던 분석자 및 분석기관이 결과에 대한 신뢰 성을 향상시키는데 표준물질로써 사용이 가능하다는 것을 의미한다. 비교결과는 Table 11에 나타내었다.

\section{4. 결 론}

토양 매질의 백석면 인증표준물질을 개발하여 편광 현미경을 사용하여 각 표준물질의 농도별 균질도, 안정 도, 인증값을 평가한 결과 다음과 같은 결론을 얻었다.

1) 토양 중 백석면 $\mathrm{CRM}$ 후보물질을 제작하여 각각 의 농도별 균질도를 편광현미경을 사용하여 측정한 결과 $\mathrm{F}$ 기각치보다 $\mathrm{F}$ 비가 작으므로, $95 \%$ 신뢰 수준 에서 균질하다고 확인하였으며, 이로써 제조된 후보물 질은 균질함을 확인할 수 있었다.

2) 토양 중 백석면 $\mathrm{CRM}$ 후보물질을 제작하여 안 정도 산출결과로부터 회귀분석을 통하여 P-값 $>0.05$, 신뢰수준 $95 \%$ 에서 6 개월 또는 12 개월 후의 후보물 질의 반복측정값에 대한 통계값이 안정함을 나타내 었다. 따라서 제조된 후보물질은 장기안정성이 있다 고 판단할 수 있다.

3) 토양 중 백석면의 후보물질 인증값은 저농도, $1 \%$ (범위, 0.25 3.00), 고농도, 4\% (범 위, 2.25 5.50)로 각각 산출되었다. 따라서 본 연구에서 개발하고자 했 던 정량분석용 인증표준물질에 대한 인증값 범위의 활 용은 분석자가 스스로 분석한 결과값을 주어진 인증값 범위와 비교 - 평가를 통해 분석능력 향상 및 결과에 대 한 신뢰성을 향상시킬 수 있을 것으로 기대된다.

4) 연구를 통해 개발된 인증표준물질은 국내의 많은 석면연구기관 및 석면관련업체의 토양 중 석면 평가 오류 발생을 줄이고, 보다 정확한 석면의 정성, 정량 분석은 최근 자연발생석면 등에 따른 광산 및 주변지 역의 지질도 작성, 광산복원, 유해성 평가를 정확하게 판단하여 효율적인 자연발생 석면 관리의 기초자료로 사용될 수 있다.

\section{감사의 글}

이 연구는 지식경제부 연구사업인 “국제상용표준물 질 인프라확대를 위한 표준물질 개발-상용화 사업”지 원에 의해 수행된 연구입니다.

\section{참고문헌}

1. U.S. Geological Survey, Mineral Commodity Summaries, 2007.

2. Becklake, Mr. American Review of Respiratory Disease, Asbestos-related diseases of the lung and other organs, 187-227 (1976).

3. 지식경제부, 국제상용표준물질 생산인프라 확대를 위 한 표준물질 개발·상용화 사업에 관한 보고서, 2011.

4. KONETIC, '석면 수입 전면 금지 보도자료', 2006.

5. 환경부, 석면안전관리법, 2011.

6. 국립환경과학원, 폐기물중 석면 분석방법 확립에 관 한 연구 최종보고서, 2007.

7. RTI, RTI Calibration Standard No. 1 INFORMATION SHEET, 2009.

8. McCrone Research Institute, The Effect of Heat on the Microscopical Properties of Asbestos, 1989.

9. American Mineralogist, 'Rapidly and Accurately Determining Refractive Indices of Asbestos Fibers by Using Dispersion Staining Method', Vol. 88, 1979-1982.

10. EPA 600-R-93-116, Method for the Determination of Asbestos in Bulk Building Materials, 1993.

11. EPA-600/M-82-020, Interim Method For The Determination Of Asbestos In Bulk Insulation Samples, 1982.

12. SO Guide 34, General requirements for the competence of reference material producers, 2009.

13. ISO Guide 30, Terms and definitions used in connection with reference materials, 1992.

14. ISO Guide 35, Reference materials-General and statistical principles for certification, 2006.

15. ISO/IEC 17025, General requirements for the competence of testing and calibration laboratories, 2005.

16. McCrone Research Institute, Advanced Asbestos Identification, APPENDICES, 2005. 